Portland State University

PDXScholar

Spring 7-20-2017

\title{
Stereotype Threat and Effects of Students' Perception of Their Math Teacher's Fairness on Their Math Self-Efficacy
}

Alexis Jocelyn DeVigal

Portland State University

Follow this and additional works at: https://pdxscholar.library.pdx.edu/open_access_etds

Part of the Educational Sociology Commons, and the Science and Mathematics Education Commons Let us know how access to this document benefits you.

\section{Recommended Citation}

DeVigal, Alexis Jocelyn, "Stereotype Threat and Effects of Students' Perception of Their Math Teacher's Fairness on Their Math Self-Efficacy" (2017). Dissertations and Theses. Paper 3999.

https://doi.org/10.15760/etd.5883

This Thesis is brought to you for free and open access. It has been accepted for inclusion in Dissertations and Theses by an authorized administrator of PDXScholar. Please contact us if we can make this document more accessible: pdxscholar@pdx.edu. 
Stereotype Threat and Effects of Students' Perception of Their Math Teacher's

Fairness on Their Math Self-Efficacy

by

Alexis Jocelyn DeVigal

A thesis submitted in partial fulfillment of the requirements for the degree of

Master of Science

in Sociology

Thesis Committee:

Dara Shifrer, Chair

Lindsey Wilkinson

Hyeyoung Woo

Portland State University

2017 


\begin{abstract}
Gender inequalities perpetuated by educational and occupational segregation may be exacerbated in part by socialization processes that occur in the years leading up to when high school students typically begin considering postsecondary options. Students' feelings of self-efficacy in certain subjects can be an important factor that informs their decisions to pursue coursework and programs. This study used stereotype theory to understand how students' perceptions of their $9^{\text {th }}$ math teacher's fairness affected their $11^{\text {th }}$ grade math efficacy and how this relationship was moderated by the gender of the student and their math teacher. Using the High School Longitudinal Study of 2009, linear regression models predicting students' math efficacy in 2012 indicated that students have higher levels of math efficacy when they perceive their math teachers as more fair, though this relationship was explained away by controls. An additional interaction term between student gender and math teacher gender revealed that girls' efficacy is more strongly affected by perceptions of their male math teachers than perceptions of their female math teachers. This finding may be explained by the persistence of stereotypes around math that assume male superiority in the subject, which leads students to see their male math teachers as true authorities in math as opposed to their female math teachers.
\end{abstract}




\section{Acknowledgments}

Foremost, I would like to thank my committee, Dara Shifrer, Lindsey Wilkinson, and Hyeyoung Woo, whose counsel was readily available and whose encouragement allowed me to pursue my own ideas.

I am grateful for the solidarity and support from my cohort, Rina James, Erin Savoia, Kyla Tompkins, and Phil Tostado. Thank you for brightening the days (and weeks and months) when getting through this thesis seemed insurmountable.

I am also so appreciative of my parents and family, many thanks for being the best cheerleaders I could hope for.

And of course, I am thankful for Eric for being by my side through all of my endeavors. 


\section{Table of Contents}

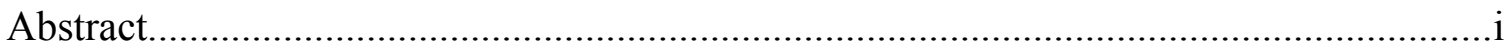

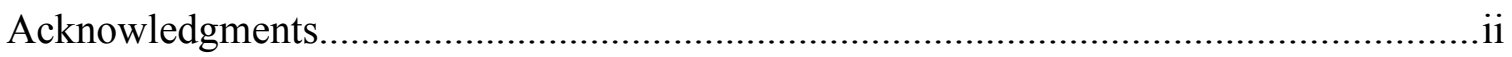

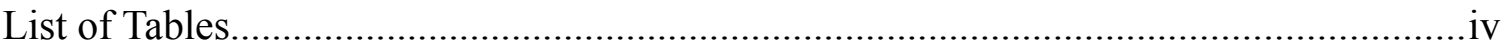

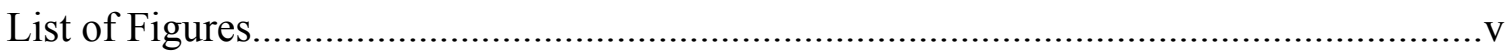

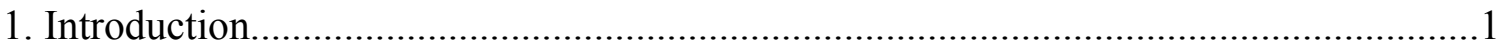

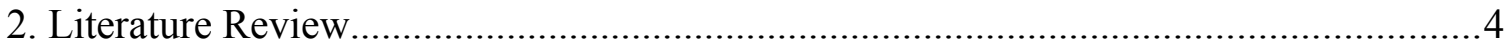

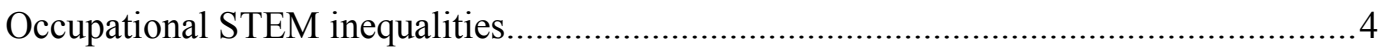

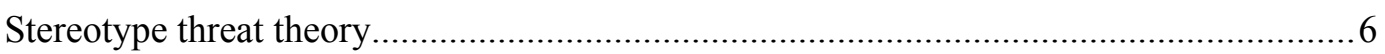

Teacher influence on students' experiences...............................................................

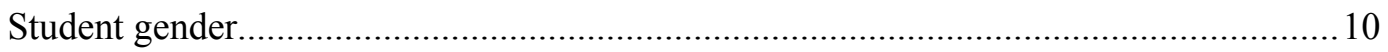

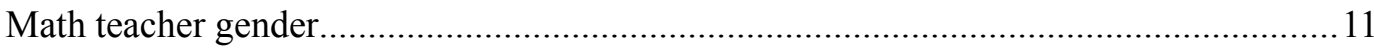

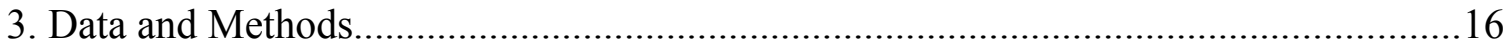

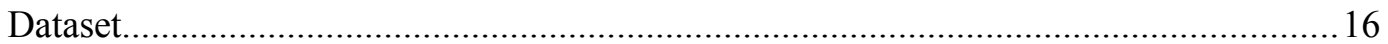

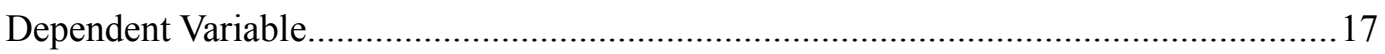

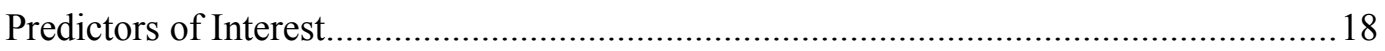

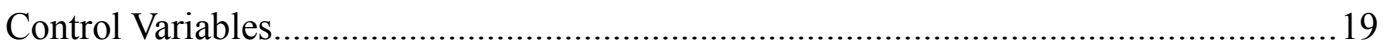

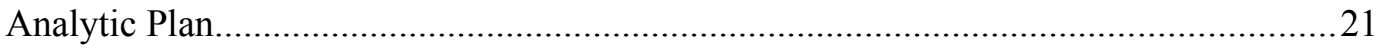

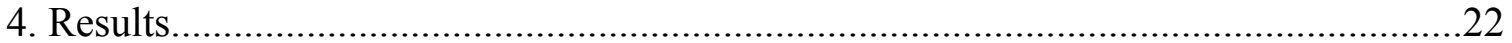

Student math efficacy by student gender..................................................................22

Student math efficacy by math teacher gender..........................................................25

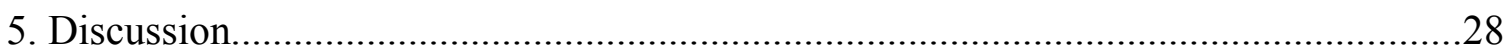

Gender disparities in students' experiences..............................................................29

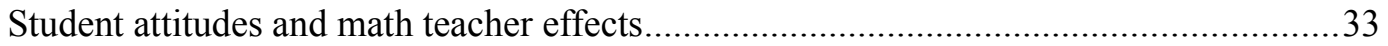

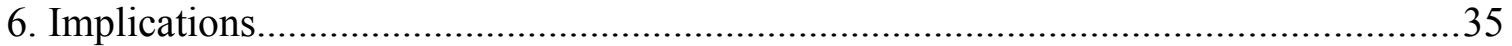

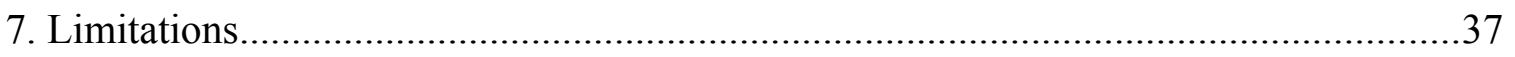

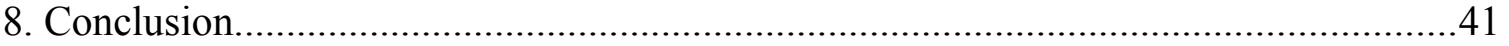

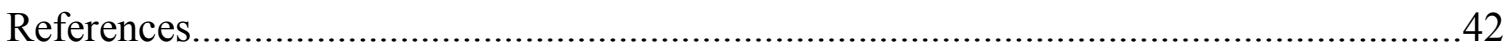

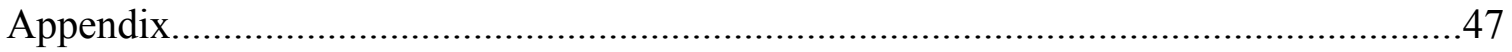




\section{List of Tables}

Table 1 Descriptive statistics of analytic sample.........................................................47

Table 2 Descriptive statistics of gender-separated models.........................................49

Table 3 Linear regression models of female students..................................................51

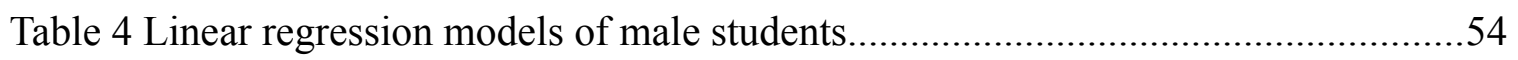

Table 5 Combined linear regression model....................................................................5 


\section{List of Figures}

Figure 1 Predicted mean values of girls' math efficacy...............................................59 


\section{Introduction}

The innovations that come from research and development in the areas of science, technology, engineering, and mathematics (STEM) are increasingly essential to aspects of day-to-day living. Despite technological advancements and new inventions that emerge from these industries, the demographics of the workers in these fields does not reflect the populations that they are meant to serve. This limits the reach of solutions from STEM research, as the perspectives and research issues focus on problems specific to men, who are still overrepresented among workers in these industries (Beede et. al. 2011; Landivar 2013). Underrepresentation of women in STEM is exacerbated by females' lower likelihood of completing a degree in a STEM field (Cover, Jones, and Watson 2011), but social psychological and gender socialization processes also play a role that result in women with STEM skills and education opting out of these fields. It is important to acknowledge and encourage an individual's choice in their personal interests and careers, but we should also be aware of the implications in how these choices at an individual level impact greater social inequalities.

It may be reasoned that as students are introduced to math stereotypes in school, they internalize the beliefs of women's inferiority in math which can carry over into decisions that come with adulthood such as college majors to pursue and careers of interest. Educational and occupational segregation that is a result of the process of withdrawal from STEM among women is not inherently negative. However, the sectors that women tend to gravitate toward are not as well-compensated as careers in STEM (Cover, Jones, and Watson 2011). Women earning lower salaries on average compared to 
men based on careers and industries they pursue may be one factor among many that contribute to the overall gender wage gap, which makes this study valuable to our understanding of this persisting social inequality.

Of particular interest in this study is the process of withdrawing from STEM, a more lucrative career path, that can be spurred by feelings of self-efficacy and informed by experiences in high school. Disparities in students' efficacy, especially in math, is becoming a more compelling argument for persisting gender segregation in STEM education and occupations. That is, performance and a student's level of achievement is not highlighted as a factor that contributes to fewer girls pursuing STEM because they have similar rates of math achievement as boys (Correll 2011; Herbert and Stipek 2005). So, students may rely more on their feelings of math self-efficacy than their actual achievement, such that those who have lower levels of math efficacy opt out of these courses and careers due to feeling incapable of success in these fields. Thus, the investigation of pivotal classroom experiences for students in high school and how these experiences contribute to persisting educational and occupational segregation by gender motivates the following study.

In this paper, I use the large, nationally representative High School Longitudinal Study of 2009 (HSLS:09) to focus on the role of gender in perceptions of math teachers and math self-efficacy among high school students. My research questions are as follows:

1. How are students' 11 th grade math efficacy affected by their perceptions of their 9th grade math teacher's fairness? 
2. Does this relationship vary depending on the gender of the student and their math teacher?

With data from the HSLS:09, I utilize the longitudinal measurement of students' math efficacy to see how teachers' influence holds over time. HSLS's wide breadth of data collection also facilitates exploring the moderating influence of student and teacher gender.

In this study, I use stereotype threat theory to investigate the way teachers' behavior may be part of socialization processes in high school that inform students' math efficacy. It is possible that some aspects of interactions with math teachers mimic the conditions an individual can experience in stereotype threat situations that assume males are superior at math to females on students' math efficacy. Math teachers are one source of feedback that contributes to students' overall school experience who also largely shape the classroom experiences that students have in math courses. Students may be particularly sensitive to teachers' behaviors that suggest some degree of belief in or rejection of math stereotypes around gender, especially because teachers play such a central role in shaping the learning environment of the classroom. The attitudes that students detect from their math teachers' behavior may inform the opinions they have about their own efficacy and abilities in math. In addition to having implications for how design professional development for high school math teachers, this study contributes to the sociology of education literature. 


\section{Literature Review}

\section{Occupational STEM inequalities}

The industries of science, technology, engineering, and mathematics (STEM) have the potential to make incredible contributions to society by driving innovation and progress toward solutions to widespread problems. The focus of STEM research, though, is undoubtedly biased by the characteristics of its workforce. Today, women make up $48 \%$ of the total workforce in the United States, but only $24 \%$ of STEM workers (Beede et. al. 2011). Wages in these fields are typically higher than mean wages in the United States, and while they often require at least a bachelor's degree, not all qualified workers are gaining employment in these industries (Cover, Jones, and Watson 2011). Women are on average surpassing the educational attainment of men (Buchmann, DiPrete, and McDaniel 2008). However, women are less likely to graduate with degrees related to science and engineering (Landivar 2013). Disparities are evident even among those who achieve a STEM degree. Thirty one percent of males with a science or engineering degree are employed in a STEM occupation while only $15 \%$ of females with the same degree are employed in a similar occupation (Beede et. al. 2011; Landivar 2013). A well-prepared and diverse STEM workforce depends on identifying the mechanism that lead to gender disparities in occupation and educational attainment in STEM.

Research finds both structural and social psychological forces influence women's decisions to choose and persist in STEM fields. Job and workplace demands conflicting with other obligations are often cited as a barrier to more women working in STEM, though some studies do not find that women's family plans predict their work anymore 
than men's family plans do (Cech et. al. 2011). Other studies highlight personality traits measured by self-reports, such as a person's level of conscientiousness and extraversion (Alcock et. al. 2014), or distaste for the competitive nature of STEM fields (Kamas and Preston 2011) as individual characteristics that lead to fewer women seeking employment in STEM fields. However, it may be argued that these perceptions of self in women are heavily influenced by gender socialization processes in adolescence, which occur much earlier in life than career considerations.

While it is crucial to note the ways that interpersonal interactions act as barriers for some women's persistence in STEM, it is also important to analyze how structural forces foster discouraging environments. Women often name "chilly" workplaces and classrooms as reasons for switching out of STEM occupations and programs (Cech et. al. 2011; Ma and Liu 2015; Salter and Persaud 2003). One argument has stated that women simply perform poorly compared to men and elicit more negative feedback from coworkers and instructors, though there is a wealth of evidence that male and female levels of math achievement are actually very similar (Buchmann et. al. 2008; Louis and Mistele 2011). Studies reveal that women feel discouraged to speak up and ask questions in certain settings and generally perceive that their perspectives are not valued in math and science classes (Salter and Persaud 2003). Thus, subjective experiences that are unique to women in STEM fields shed light on societal expectations that act structurally in the classroom and the workplace to deter them from these industries. Unwelcoming climates are in part a product of instructor and managerial policies, making this an 
important pathway whereby policy changes could increase the participation of women in STEM fields.

\section{Stereotype threat theory}

To understand the role of students' subjective experiences on academic outcomes, I draw from stereotype threat theory. This is the idea that cultural expectations and negative stereotypes about a particular social group impacts one's performance if there is a possibility of being judged poorly according to existing stereotypes (Spencer, Steele, and Quinn 1999). The negative effect on women's math performance is observed in several experimental studies and meta-analyses. Women underperform in testing conditions where they are told that math assessments reveal gender differences compared to women who are told that there are no differences between men and women's scores (Huguet and Regnér 2007; Johnson et. al. 2012; Maloney, Schaeffer, and Beilock 2013; Nguyen and Ryan 2008; Spencer, Steele, and Quinn 1999). Conversely, the same effect on performance is inconsistent for men in the face of stereotypes that are supposed to favor them. In conditions where men are told that math assessments are not supposed to reveal gender differences, there is no effect (Johnson et. al. 2012) or a slight decrease in their performance (Spencer, Steele, and Quinn 1999). Even at the national level, the degree to which an entire country's population subscribes to math stereotypes predicts gender differences in 8th grade math (Nosek et. al. 2009). While this study does not observe stereotype threat directly, this theoretical framework can aid the understanding of experiences students have with math teachers that might serve as a similar process where stereotype threat is activated by certain behavior from teachers toward students. Research 
in the last couple decades explores the way math stereotypes act in tandem with other aspects of students' experiences at school to affect concrete outcomes such as gender gaps in attainment and participation in STEM fields.

There are many aspects of students' classroom behavior and attitudes that are affected by math stereotypes. External sources of feedback, such as interactions with teachers and grades, may be interpreted differently depending on students' reactions to math stereotypes. Any number of negative emotional reactions, such as apprehension around being negatively evaluated, discourage students from fully participating or engaging during class and hinder math performance (Appleton, Christenson, and Furlong 2008; Gunderson et. al. 2012; Patrick, Ryan, and Kaplan 2007). This can be a two-way relationship, where poor performance feeds back into lower classroom engagement and higher math anxiety leading ultimately to more girls being evaluated less favorably than boys by their teachers (Robinson-Cimpian et. al. 2014). Grades and teacher feedback become external sources of negative evaluation. Girls also become their own sources of negative evaluation, depending on how much they internalize and subscribe to math stereotypes. This can lower the way girls assess their own ability to succeed in math and their overall level of math efficacy.

Research of girls' self-evaluations reveals that they see themselves as performing poorly compared to boys, regardless of actual achievement, which is evidence of the existence of math stereotypes (Correll 2011; Herbert and Stipek 2005; Nosek et. al. 2002). Lower levels of math efficacy in girls is associated with avoidant behaviors, such as less participation in classroom settings and lower likelihoods of girls enrolling in 
higher level math courses (Correll 2001; Lent et. al. 2008; Patrick, Ryan, and Kaplan 2007). Girls' efficacy has also been found to be more closely related to their overall achievement in math more so than their general interest in the subject (Howard 2016; Legewie and DiPrete 2012). For this study, I focus specifically on how students' efficacy varies in different learning conditions, which are in part influenced by math teachers. The impact of math teachers is particularly important because they occupy an advantageous position to combat negative impacts on girls' academic attitudes, which is explored in the next section.

\section{Teacher influence on students' experiences}

Instead of relying on stereotypes to inform students' efficacy, positive interactions with math teachers can give students an external source of validation for their math efficacy. Teachers evaluate students in many concrete ways, through grades and test scores, but also affect the learning environment through teaching practices and day-today interactions with students. Students may be uniquely sensitive or oblivious to indirect teacher feedback, but the effect that teacher feedback has on students is ultimately shaped by what the students notice and internalize in reinforcing their math efficacy. Research finds that positive teacher relationships boosts students' engagement in class (Boaler and Sengupta-Irving 2016; Duncan-Andrade 2008; Kelly and Zhang 2016; Marchand and Gutierrez 2017; Roorda et. al. 2011) and improves students' overall perception of school, as evidenced by lower dropout rates (Barile et. al. 2010; Bergeron, Chouinard, and Janosz 2011). Better relationships and emotional associations with school makes the classroom 
less of a site for anxiety then, and instead encourages classroom behavior that elicits positive feedback and builds students' efficacy.

Exact characteristics of beneficial classroom practices and teaching methods varies between studies. Students have mentioned that helpful and encouraging behaviors that teachers exhibit can be anything from hands-on lessons (Wenglinsky 2002), embracing different perspectives (Boaler and Sengupta-Irving 2016; Duncan-Andrade 2008), or managing stress associated with school (Cordero et. al. 2010; Emamjomeh and Bahrami 2015; Falco, Summers, and Bauman 2010). This study relies on students' perspectives of whether their math teacher is fair. A teacher who is perceived as unfairly treating students based on something other than their performance in math may reinforce math stereotypes about girls' inferiority. Conversely, when students perceive their math teacher as treating students fairly, this may create a classroom environment in which students ignore math stereotypes. Perceptions of whether the same classroom is welcoming are likely to vary depending on background and personal traits, but subjective perceptions are likely a better measure of the psychological impact of the classroom than some objective perception of the classroom climate. Therefore, I hypothesize that students who have more positive perceptions of their math teachers will also have greater math efficacy.

In this study, students' perceptions of school and their teachers might be influenced by the nature of their experiences in school. Students who excel academically, for example, might have fewer negative interactions with teachers because of their success (Bergeron et. al. 2011; Herbert and Stipek 2005). The lack of disciplinary issues 
that high-achieving students tend to avoid can result in more positive associations with their teachers and greater efficacy toward their capabilities in school. The level of academic achievement and students' overall relationship toward school are important as it informs students' perceptions of their teachers and learning experiences, so I control these factors in my study. Other background characteristics, such as students' socioeconomic status and race are found to shape their experience in school and their level of preparation for academic work (Roorda, et. al. 2011), so I also include controls for household characteristics in this study. A students' gender may also affect their experiences in school, which is explored in the next section.

\section{Student gender}

A student's sex may change their perception of a teacher. A New Zealand study finds that in classes of teachers who have negative attitudes and expectations about certain racial groups, students of that stereotyped group have lower levels of achievement compared to classes whose teachers do not share those biases (Peterson et. al. 2016). Teachers' attitudes can also work to help students, as encouragement from teachers boosts girls' motivation and engagement in class (Korur and Eryilmaz 2012). Students that fear negative judgment may be more prone to notice when teachers confirm or reject the ideas of a certain group's superiority according to existing stereotypes. However, a study that looks at the intersection of students' race and gender finds that White females, not women of color who are would be facing two intersections of negative stereotypes, are the most affected by poor teacher evaluations (Riegle-Crumb and Humphries 2012). The gender bias may be "so socially ingrained that it is hard to grasp and, therefore, hard to resist, 
while at the same time teachers may be keenly aware of race/ethnicity in the classroom, and any opinion or action on their part would suggest discrimination" (Riegle-Crumb and Humphries 2012:313-4). This leads me to focus on how math stereotypes affects students' math efficacy based on their gender.

Female students are the most susceptible to the influence of math stereotypes because they are the ones expected to fail in math. An extra boost to girls' attitudes that comes from their math teachers, then, would be beneficial because if they have internalized math stereotypes, they will have an "expert" contradicting that belief with positive feedback. Research shows that girls were more likely to participate in positive learning environments than boys (Korur and Eryilmaz 2012; Roorda et. al. 2011) and girls are also more discouraged by hostile learning environments than boys (Salter and Persaud 2003). Additionally, teachers whose behaviors or attitudes reflect some belief in math stereotypes negatively affect girls' experiences but not boys (Beilock et. al. 2010). Research is definitely mixed since some studies find no gender difference on the effect of positive perceptions of teachers in primary school children (Upadyaya and Eccles 2015). As students get older, there is evidence that students' perceptions of their math teachers affect math attitudes toward middle school (Winters et. al. 2013) and high school (Legewie and DiPrete 2012) when expectations around gender become more pressing. Therefore, I hypothesize that girls' efficacy will be more impacted by perceptions of their teachers as fair than the efficacy of boys.

Math teacher gender 
Finally, a teacher's feedback may be valued and interpreted differently depending on the teacher's gender. Compared to female teachers in a meta-analysis, male teachers are unexpectedly associated with slightly greater positive effects on students' engagement (Roorda et. al. 2011). Female teachers tend to be more frequently associated with more positive learning environments that benefit students (Cornelius-White 2007) because traditional gender roles portray women as more nurturing and better equipped to cultivate students' efficacy. Research suggests that a teacher's gender can create certain expectations for students that, when also considering students' gender, moderates how students experience learning environments. One way students learn gender-appropriate behavior is by observing adults with whom they share their gender, and teachers are some of the only adults who serve as academic role models for students aside from parents or guardians (Gunderson et. al. 2012). Research finds some encouraging implications for positive role models in students' lives for a variety of academic outcomes that are not just limited to students' efficacy.

In studies of teachers' influence as role models, the characteristics of the role model matters. This is especially true for girls who may lack role models in STEM occupations outside of any female teachers they have who teach math or science classes. Having role models is important in addressing students' concerns about negative stereotypes that exist about their own capabilities in certain fields, which can be assuaged by the presence of successful adults who share meaningful identities with students (Gunderson et. al. 2012). Female teachers who are nervous about girls' performance in math transmit their anxieties to their students which results in lower efficacy for girls in 
math since that role model displays apprehension toward the subject (Beilock et. al. 2010). Conversely, an experimental study found girls and boys benefit from exposure to a role model of any gender that is portrayed as hardworking in math as opposed to someone who is considered naturally gifted in the subject (Bagès and Maritnot 2011). These findings suggest that students' efficacy can benefit from role models that convey the value of individual effort. Mentorship interventions that provide positive, confident role models from STEM industries to girls in elementary and middle school find that these programs are associated with improved levels of efficacy in math for girls (Holmes et. al. 2012; Tyler-Wood et. al. 2012). It is unclear if the benefits come from having a confident role model in math to boost their efficacy or from the curriculum and enrichment activities associated with these programs. However, the findings from research on beneficial mentor characteristics are helpful to shape policies around teachers' effect on students' learning experiences.

The effect of teacher gender on students' experiences is still a topic of debate. It does appear that there may be more opportunity to affect girls' math efficacy, and achievement indirectly, through female math teachers. Girls who have high levels of achievement in math benefit from female teachers' positive attitudes in math courses while girls who are average or low achieving students do not experience the same boost to their math attitudes (Carrell 2009). There is some agreement that girls' classroom engagement increases with female math teachers more so than male teachers because they fear less judgment from women (Roorda et. al. 2011; Shapiro and Williams 2012). Girls' participation is inconsistently affected by female math teachers, though there does 
seem to be hope for positive interventions in this part of a student's classroom experience. Feedback from male teachers may be more valuable because girls may believe that they are experts in math, but overall, research findings are mixed. Male math teachers sometimes increase the fear of being stereotyped among girls (Shapiro and Williams 2012), but are also associated with better math achievement for girls and boys (Roorda et. al. 2011). This may be due to differences in teacher assignment by gender, so I control for math course level in my study (Cho 2012; Dee 2006, 2007). Given the findings in the current literature, I hypothesize that students' math attitudes will be most strongly affected by perceptions of their math teachers if they share their gender.

It is important to account for the potentially spurious influences of a student's background, their school characteristics, and their experiences in math courses because these factors relate to both students' perceptions of their math teacher's fairness and their math efficacy. Essentially, the socioeconomic status of a student's household and their parent's level of education contributes in part to how academically prepared a student is (Bergeron et. al. 2011; Roorda et. al. 2011). Being more prepared for school can lead to more success and positive feedback in class that would affect a student's subjective experiences in class, including their perceptions of their teachers and their feelings of efficacy in many subjects. A student's overall relationship toward school can also shape their subjective experiences in class (Gunderson et. al. 2012; Patrick, Ryan, and Kaplan 2007), so this attitude is also accounted for in this study. The controls I include also contribute to the level of math students reach by high school, and the ability to handle more advanced course material and pursue those classes can relate to both students' 
perceptions of their math teacher's fairness and their math efficacy (Dee 2006, 2007), so I account for characteristics of students' math classes in this study.

In sum, my hypotheses for this study are as follows:

H1: Students who perceived their 9th grade math teacher as more fair will have higher levels of math efficacy in the 11th grade.

H2: Students' perceptions of math teacher fairness will have a stronger effect on female students' math efficacy than that of male students.

H3: Perceptions of teacher fairness will exert a stronger effect on students' efficacy if their teacher shares their gender. 


\section{Data and Methods}

\section{Dataset}

The High School Longitudinal Study of 2009 (HSLS:2009) is conducted by the National Center for Education Statistics (NCES), the primary federal entity for collecting and analyzing data related to education in the United States. This is a nationally representative dataset of 9th graders in the US in 2009. Sampling focused on 944 public and private high schools. Within each school, an average of 25 students in 9th grade were selected which resulted in a sample of about 24,000 students. The dataset includes survey responses from students with additional survey responses from students' parents, students' math and science teachers, school administrators, and school counselors. It includes a math assessment in the base year of data collection, and the NCES has published follow up data from the spring of 2012 (most students' 11th grade year) and the spring of 2013 (their expected graduation year). Subsequent data collection is planned for 2016 and 2021 to learn about participants' postsecondary experiences, choices, decisions, and attainment in adulthood. Student questionnaires focus on students' trajectories in education and the workforce with questions pertaining to when, why, and how students choose majors and careers with a particular focus on science, technology, engineering, and math (STEM) trajectories in school and in adulthood.

This study used publicly-available data from student and teacher questionnaires in the base year (2009) and from student questionnaires first follow up year (2012). All analyses are weighted with the first follow-up student analytic weight to adjust for the complex sampling design. Students were excluded if they were missing values on the 
dependent variable $(\mathrm{n}=2,928)$ or were not enrolled in a math class during the base year of data collection $(\mathrm{n}=497)$. The dependent variable is a constructed mean scale, which I discuss in detail below, that requires a minimum of two out of the four survey items so that even if students only answered half of the questions required for the scale, they were assigned a value. The final analytic sample includes 20,078 students. Mean and mode imputation addressed missing values on all independent variables. Descriptive statistics on all variables used in analyses are included in Table 1.

[Table 1 about here.]

The selection criteria for the analytic sample resulted in a number of differences between the analytic sample and excluded cases. The proportion of females in the analytic sample was 12 points higher than that of male students compared to the proportion of females to males in excluded cases. Additionally, there were slightly fewer Black students and slightly more White students in the analytic sample than the cases excluded from analyses. Students' backgrounds were mostly similar in terms of parent and school characteristics, though students in the analytic sample came from households with an average of $\$ 20,000$ more yearly income than students excluded from analyses. The only notable differences in students' school experiences were in students' math achievement and students' educational expectations. Students in the analytic sample scored 6.1 points higher on average than students excluded from analyses. Proportionally, $8 \%$ more students in the analytic sample intended to pursue a bachelor's degree than students excluded from analyses.

\section{Dependent Variable}


The dependent variable in this study is a constructed mean scale of students' math efficacy in 2012 that uses the same survey items in the math efficacy scale constructed by NCES from the 2009 questionnaire. The constructed scale in this study combines 4-point Likert scale questions about a student's ability to understand their math textbook, do well on tests and assignments, and their certainty that they can master skills in their math class in 2012. These items were only administered to students who indicated that they took a math course in the spring of 2012, so students who were not enrolled in a math class at this time $(\mathrm{n}=4,612)$ did not have an option to answer these questions. If a student was enrolled in more than one math class, the questions were worded so that the most difficult level of math was addressed in the survey. Of the four survey items, the number of students who skipped a question ranged from 576 to 611 . This item is specific to students' experience with their math class in the academic year, which may capture students' attitudes about a particular aspect of the course, such as the teacher or the level of math, rather than their attitudes toward math in general. I include controls in my analyses to help account for the influence of these factors which are detailed below. Students who provide at least two out of four responses are assigned a number value. Higher values on this scale indicate that a student is more confident that they can perform the tasks related to their math courses in 2012 (Cronbach's alpha $=0.89$ ).

\section{Predictors of Interest}

The predictor of interest in this study is a constructed mean scale that measures students' perceptions about their math teacher's fairness in 2009. It combines 4-point Likert scale questions that include how much a student agrees that their math teacher 
values and listens to student's ideas, treats students with respect, treats every student fairly, treats some students better than others, and treats males and females differently. Two survey items are reverse coded for uniform directionality. The item that indicates that a teacher treats males and females differently is reverse coded under the assumption that a teacher displays preferential treatment toward boys that aligns with stereotypes that uphold the superiority of boys' math abilities. Higher scores indicate that a student perceived their math teacher in 2009 as treating students more fairly than students with a lower score (Cronbach's alpha $=0.84)$. Preliminary analyses on math teachers' treatment of students based on gender did not reveal any significant associations with students' math efficacy, so the predictor of interest contains all survey items pertaining to the overall perceptions of math teacher fairness.

\section{Control Variables}

Because student's background or experiences in school may affect their perceptions of math teacher fairness and their math efficacy, these factors are controlled for in regression analyses. Control variables include students' race, parents' occupation and educational attainment, household income, school region and locale, students' pride in their school, students' math scores on assessments, students' educational expectations, and the level of students' 9th grade math course. All control variables were measured in 2009 unless otherwise specified. The measure of students' math efficacy in 2009 consists of identical survey items in constructed scale for their math efficacy in 2012, though the control variable is mean-centered by the NCES. The HSLS:2009 race categories include White, Black, Hispanic, Asian, Native Hawaiian or other Pacific Islander, American 
Indian or Alaska Native, and students who identify with more than one race. Native Hawaiian or other Pacific Islander, American Indian or Alaska Native, and students who identified with more than one race are combined into one category to maintain appropriate cell sizes for analyses. Students' pride in school is measured to capture the quality of students' relationship to their school as this can affect their experiences in classes. Students' math achievement is based on students' item response theory (IRT) scores on the math assessment during 2009. Students' educational expectations are measured based on whether students indicated that they planned to enroll in a bachelor's degree program during their first year after high school. I construct a categorical indicator for students' highest level of math attempted during 9th grade (lower than Algebra 1, Algebra 1, Geometry, higher than Geometry) from students' reports. For example, if students indicated that they were enrolled in both Algebra 1 and Geometry, they are assigned to Geometry.

All measures of parent characteristics distinguish between students' mother and father and could include stepparents, adopted parents, and other non-biological guardians. Parents' educational attainment includes a category for students without a parent or guardian. Parents' occupations are classified as STEM (life and physical science, engineering, mathematics, information technology, social science, architecture, health, any occupation split between two sub-domains, and unspecified sub-domains) or nonSTEM (management, business, finance, legal, education, arts, design, media, protective service, food preparation and serving, building and grounds maintenance, personal care and service, sales, office and administrative support, farming, fishing, forestry, 
construction, extraction, installation, maintenance, repair, production, transportation, and military domains), with a third category for students with no mother or father. Although treated like a scale measure, HSLS measures yearly household income categorically, with values ranging from less than $\$ 15,000$ to more than $\$ 235,000$. Categorical measures also capture each student's schools' urbanicity (city, suburb, town, or rural) and region (Northeast, South, Midwest, or Western).

\section{Analytic Plan}

Linear regression models predicting students' math efficacy in 2012 will show whether students' efficacy varies as a function of their perceptions of math teacher fairness. These models are separated by student gender, as opposed to including male and female students in the one model, to investigate whether gender moderates the relationship between student perceptions of teacher fairness and student math efficacy. The first model will show the baseline relationship between the two variables. The second model will add students' math efficacy from 2009 to determine whether student's math efficacy in 2012 is simply a product of their efficacy in 9th grade or if the effect that perceptions of students' 9th grade math teachers' fairness holds over time. The third model will add students' individual characteristics, variables related to their experiences in school, math course characteristics, parents' characteristics, household characteristics, and school characteristics to account for spurious influences. The fourth model will add the interaction variable between math teacher gender and students' perception of math teacher fairness to investigate how math efficacy varies when students share their gender with their math teacher. 


\section{Results}

[Insert Table 2 about here.]

Table 2 uses descriptive statistics to show gender differences in most personal and background characteristics were not drastic. Most notably, female and male students' perceptions of math teacher fairness is almost identical. In a notable difference, female students have an average math efficacy of -0.01 in 2009 while male students have an average math efficacy of 0.14 in 2009 . This is consistent with previous literature that females are more likely to assess their math skills lower than males even if they have similar levels of actual math achievement. Also consistent with previous studies' findings that gender differences in math achievement are not marked, female students' average score on the standardized test administered by NCES is 40.87 while male students' average is 40.98 . The other notable difference is that $63.0 \%$ of female students in 9 th grade expected to pursue a bachelor's degree during their first year out of high school, compared to $56.6 \%$ of male students. Substantively, this means that female students started with lower levels of math efficacy in 9th grade even though they exhibit almost identical levels of math achievement on average.

Student math efficacy by student gender

[Insert Table 3 and Table 4 here.]

Tables 3 and 4 show coefficients from linear regression models predicting students' math efficacy with Table 3 focused on female students and Table 4 on male students to determine if student gender moderates the relationship between students' perception of their math teacher's fairness and students' self-efficacy. Based on Model 1 
in Table 3, female students' math efficacy increases by 0.14 on average with each oneunit increase in their perception of their math teacher's fairness. This relationship is statistically significant $(\mathrm{p}<0.001)$. Based on Model 1 in Table 4, male students' math efficacy increases by 0.15 on average with each one-unit increase in perceptions of their math teacher's fairness. This relationship is also statistically significant $(\mathrm{p}<0.001)$. These findings support my first hypothesis that a student's math efficacy will increase when they perceive their math teachers as more fair. Both female and male students' math efficacy appears to benefit from these positive experiences to similar degrees.

I control for the possibility that students' math efficacy in 2009 explains the variation in their math efficacy in 2012 by adding the first measure of efficacy in Model 2 for Tables 3 and 4 as students' perceptions of their math teachers may be largely influenced by previous experiences around math classes in general. Based on Model 2 in Table 3, female students' math efficacy increases by 0.03 on average with each one-unit increase in perceptions of their math teacher's fairness net of the effect of their math efficacy in 2009, which is 0.11 lower than the effect in the first model. This relationship is statistically significant $(\mathrm{p}<0.01)$. Similarly, based on Model 2 in Table 4, male students' math efficacy increases by 0.03 on average with each one-unit increase in perceptions of their math teacher's fairness net of the effect of their math efficacy in 2009, which is 0.12 lower than the effect in the first model. This relationship is also statistically significant $(\mathrm{p}<0.01)$. For both female and male students, the strength of students' perceptions of their math teachers in 2009 has a much smaller, but still significant, impact on their math 
efficacy when also considering their more recent perceptions of their math teachers in 2012.

When considering the full models with all controls, however, the relationship between students' perceptions of math teacher fairness and math efficacy changes which is evident by the third models. According to Model 3 in Table 3, the relationship between female students' perceptions of their math teacher's fairness and their math efficacy loses significance after adding control variables. Similarly, this same relationship between perceptions of their math teacher's fairness and math efficacy loses statistical significance for male students (Model 3 in Table 4). This means that, net of controls, perceptions of math teacher fairness in 2009 do not impact female or male students' math efficacy in 2012.

[Insert Table 5 about here.]

To investigate whether girls' math efficacy is more strongly affected by perceptions of their math teacher's fairness, I conduct t-tests of the coefficients for female and male students' perceptions of their math teacher's fairness from Model 3 in both Table 3 and 4. Thus, according to Table 5, there is a difference between the coefficient for female and male students $(\mathrm{t}=-0.05)$. However, this difference is not statistically significant. According to these analyses, then, my hypothesis that female students will benefit more from perceiving their math teachers as more fair is not supported. Rather, it seems that female and male student's math efficacy is explained by a student's background, household characteristics, and school experiences more so than behaviors from and perceptions of their math teachers. 


\section{Student math efficacy by math teacher gender}

To whether math teacher gender moderates these relationships, an interaction variable between students' 2009 perceptions of their math teacher as fair and math teacher gender in 2009 is added to the fourth models. Model 4 in Table 3 shows that this interaction is statistically significant for female students. In Table 3, Model 4, girls' efficacy increases on average by 0.16 when they have a female math teacher compared to when they have a male math teacher. Female students' math efficacy in 2012 increases by 0.06 on average for each one-unit increase in perceptions of their male math teacher's fairness. The positive effect of perceiving their math teacher as fair, though, is 0.05 units lower $(0.06-0.05=0.01)$ if their teacher is female rather than male. In Table 3, Model 4, girls' efficacy increases on average by 0.16 when they have a female math teacher compared to when they have a male math teacher. According to the fourth model, female students, math efficacy is not as strongly impacted by perceptions of female math teacher's fairness. It seems that for female students, the way they perceive their male math teachers has more of an impact on their math efficacy than perceptions of their female math teachers. Figure 1 provides a graphical representation of this interaction to facilitate interpretation.

Figure 1 shows differences by math teacher gender in female students' predicted mean math efficacy levels. Moving from left to right, the x-axis progresses from female students who perceive unfair treatment from their math teachers to female students with the highest perceptions of math teacher fairness. The blue line indicates predicted mean math efficacy levels of students with male math teachers, while green line marks the 
same measure for students with female math teachers. The line for female students with male math teachers has a steeper slope than the line for female students with female math teachers. This means that female students' math efficacy is more strongly and negatively affected by unfair male math teachers than unfair female math teachers. As evidenced by the right end of Figure 1, students who perceived their math teachers as fair have greater levels of math efficacy on average when they have male math teachers compared to female students with female math teachers. Both of these findings do not support my third hypothesis that female students will be more positively affected by female math teachers than male math teachers. Instead, it seems that teachers' influence on female students' efficacy is stronger when coming from a male math teacher.

In contrast, there is still no statistically significant difference in levels of male students' math efficacy regardless of whether students had a female math teacher or a male math teacher (Model 4 in Table 4). In Table 4, Model 4, boys' math efficacy decreases by 0.11 on average when their math teacher is female rather than male. Boys' efficacy decreases by 0.02 on average for each one-unit increase in their perceptions of their male math teacher's fairness. The effect of perceiving their female math teacher as fair is 0.04 points greater $(-0.02+0.04=0.02)$ when their math teacher is female rather than male, though these findings are not statistically significant. Male students, whose efficacy is likely not affected by math stereotypes, do not exhibit any added benefit with positive teacher feedback according to my analyses. Since this relationship is not statistically significant for male students, this suggests that there is some aspect of teacher characteristics and behavior that affects only female students' math efficacy. I argue that 
my analyses observe how math teacher support negates effects of stereotype threat that are unique to female students because math stereotypes assume women's inferiority in math to men. Thus, my third hypothesis that students are more affected by experiences with teachers that share their gender is not supported. 


\section{Discussion}

The purpose of this study was to examine how students' math efficacy in 11th grade is associated with perceptions of their math teacher's fairness in 9th grade. Using stereotype threat theory to understand gender differences in math class experiences, research suggests that girls are negatively affected by ideas that they are inferior mathematicians compared to boys. That is, when girls perceive that they are being treated unfairly in math classes, these perceptions contribute to the reinforcement of math stereotypes based on their gender. When both the gender of the student and math teacher is considered, the effect of students' experiences in 9th grade do have an effect on their math efficacy in 11th grade. For boys, there are still no significant benefits or detriments to their math efficacy based on their perceptions of their math teacher as fair, regardless of the gender of their teacher. In addition to teachers having a stronger effect on female math efficacy than male efficacy, girls appear to be more strongly affected by perceptions of their male math teachers than their female math teachers. Additionally, girls' efficacy suffers more when their male math teachers are perceived as unfair compared to when their female math teachers are seen similarly. Conversely, girls' confidence is also boosted more when their male math teachers are perceived as fair compared to when their female math teachers are seen similarly. The results from this study suggest that positive interactions with teachers are important for encouraging girls who are hesitant or discouraged to engage in math classes and programs based on misinformed and outdated notions of students' math efficacy and academic capabilities. These findings may run 
counter to the idea that under-represented students benefit most from mentors or role models who share important identities, such as gender.

\section{Gender disparities in students'experiences}

Research of how different teaching styles affect students' efficacy find that boys and girls do not experience this aspect of school in the same way. Building upon the mixed findings in previous literature, this study contributes to our understanding of girls' classroom experiences and how teachers' behavior is particularly impactful to students' math efficacy. Girls are heavily influenced by the gender biases they detect from their teachers, which is especially true if their math teacher is male. Falco, Summers, and Bauman's (2010) evaluation of a middle school program in Arizona observed how math classes that incorporated curriculum targeting students' self-beliefs in math, including their math efficacy, resulted in a greater boost to girls' math efficacy who received the interventions than girls who did not. Similarly, results in this study indicate that girls' efficacy improves when teachers are more fair and do not obviously adhere to math stereotypes. In my study and Falco, Summers, and Bauman's evaluation, there is evidence that girls benefit when teachers encourage them to have more favorable views of their academic capabilities and efficacy.

One reason that teacher influence is more impactful for girls in math than for boys may be partially explained by the existence of stereotypes that assume girls' inferiority as mathematicians. When cultural expectations align with teachers' evaluation of students, girls are informed by multiple sources about their academic potential. That is, when girls encounter unfair treatment in math classes, this can reinforce negative stereotypes that 
exist around their math abilities compared to boys. This can contribute to girls' lower self-assessments of their capabilities on math in response to discouraging learning experiences, possibly spurring lower classroom engagement and eventual withdrawal from math courses and programs. Conversely, research of math interventions that aim to combat teacher biases find that when teachers are perceived as fairly judging students on their math ability as opposed to their gender, students do better. As seen in the Arizona study, there is a possibility for girls to benefit from learning environments that are sensitive to the negative effects of stereotypes and confront the assumptions of girls' inferiority as mathematicians.

On a positive note, girls whose teachers cultivate fair learning environments boost girls' math efficacy. However, the benefit is greater for girls with male math teachers as opposed to female math teachers. Results in this current study indicate that perceptions of male teachers' unfair teaching practices harm girls' math efficacy more so than female teachers who have similar classroom environments. Findings in this study also indicate that positive learning experiences with male math teachers are more beneficial to girls than experiences with female math teachers, so students are not more affected by learning experiences with teachers that share their gender. It is possible that role models might not be as effective at addressing students who acknowledge and internalize math stereotypes in high school. However, there are mentorship interventions in elementary and middle schools (Holmes et. al. 2012; Tyler-Wood et. al. 2012) that do improve girls' efficacy. These studies highlight the importance of instilling positive ideas of girls' academic 
capabilities that can safeguard them from internalizing stereotypes of females' mathematic inferiority.

Substantively, findings in this study also suggest that girls take male math teachers more seriously than female math teachers. Effects of a teacher's gender in this study are likely shaped by the stereotypes that are specific to math. This may also indicate that girls, to a certain extent, adhere to stereotypes about male superiority in math that contributes to their perceptions of legitimacy of their math teachers depending on that teacher's gender. Essentially, male math teachers may be recognized as more of an authority in math because female math teachers are not perceived as true experts in this domain. Thus, positive feedback from men has a more beneficial impact on girls' efficacy as they are seen as coming from someone in a genuine position of expertise. These findings mirror tenets of standpoint theory that finds women's perspectives are "disempowered" and not perceived a source of credible scientific knowledge (Chafetz 1997). As a "true" source of authority, then, male math teachers appear to be a slightly more effective means to combat negative cultural expectations of girls' math abilities than female teachers.

In contrast, efforts from female teachers may be interpreted in a different light than interactions with male math teachers. Teaching practices that target girls may be interpreted as a calculated move to cultivate interest when coming from female teachers, which can spoil the learning experience when students feel as though they are being manipulated or are forced to engage with material. Thus, girls may be more dismissive of encouragement that comes from female math teachers since, according to math 
stereotypes, their expertise and evaluations are not as distinguished as those of male math teachers. That being said, the role that student and math teacher gender plays in affecting students' math efficacy raises the subject of both individuals adherence to stereotypes in the first place. When students internalize the ideas associated with math capabilities based on gender, they have to reconcile sources of this cultural expectation from within themselves and from external sources that teacher may only partially affect. This complicates the process of dismantling math stereotypes since they originate from multiple aspects of students' lives, but it also opens doors for a wider variety of interventions to address educational inequalities around math.

Results from this study find that boys are not significantly affected by perceptions of their math teacher's fairness, regardless of whether their teacher is male or female. This suggests that the additional validation boys might get from their teachers may not be of much value to experiences in the classroom. Their efficacy in math does not appear to suffer because of the cultural expectation that boys will excel in this subject. Thus, the boost that might happen as a result of positive experiences with teachers is not as impactful for boys because they do not have the added tension of math stereotypes that contribute to lower assessments of their own abilities. Rather, it may be reasoned that the benefits of teaching practices that emphasize fairness among all students provide a separate boost to students who experience fears and anxieties toward perceptions of their academic performance.

While boys in this study do not demonstrate a change in efficacy based on perceptions of their math teachers, they may not be entirely immune to positive 
influences. There is evidence that another adult in boys' lives affect their attitudes more than math teachers. In this study, boys who had fathers in STEM occupations had slightly more confidence in their math abilities than boys whose fathers worked in occupations outside of STEM. While parents' occupation was only a control in this study, this could be a direction for future research that focuses on what motivates boys' efficacy in math. It seems that the proximity and closeness that an adult occupies in relation to male students may dictate the degree to which those interactions shape students' opinions and attitudes.

\section{Student attitudes and math teacher effects}

Research attributes a majority of students' success in school to individual traits and family contributions, which informs students of what is within the realm of possibility for their academic trajectories. In this study, results indicate that students' efficacy in math are explained more by personal and background characteristics than by experiences with their math teachers. Beginning in middle school and high school, students have more than one teacher throughout the school day, so the effect that any single teacher has on an aspect of students' attitudes or experiences may be muddled by the influence of other teachers and adults with whom students interact. Kelly and Zhang (2016) did find a boost to students' classroom engagement for certain classes where students had positive relationships with their teachers, though in this study, the measures for efficacy included items about students' math identity. It is possible that a positive learning experience in math classes with encouraging teachers help students reconsider themselves as mathematicians, not just improve assessments of their own math-related abilities. So, a more open, considerate teacher does not just encourage better self- 
assessments but also invites more reluctant students to envision themselves in potential trajectories and careers in math. 


\section{Implications}

The findings in this study are specific to stereotypes and cultural expectations around math, though there are broader explanations that may contribute to our understanding of how beliefs around social groups shape their concrete outcomes. In this study, girls' participation in math was not solely influenced by structural barriers at an institutional level, such as enrollment restrictions for advanced math courses. Girls face abstract ideas in the form of math stereotypes as an additional barrier. When these stereotypes appear to be reinforced by adults they interact with at school, this can lead to girls' underestimating their abilities and avoiding math in their academic careers. This may be applied to stereotypes that exist around social groups participating less frequently in certain types of labor or other gainful activities.

This study also highlights how research should investigate the social institutions and actors within them that contribute to persisting social inequalities. More importantly, people who occupy positions of prestige or expertise have the potential to influence opinions and attitudes that may be harnessed to reach underutilized populations. Male math teachers, for example, may be able to use math stereotypes to the advantage of unsure female students and guide them toward opportunities to participate in math in targeted interventions. Other experts within firms, such as managers or content specialists, are in similar positions to encourage greater involvement from uncertain workers. Conversely, findings in this study also illuminate the need for experts to check their biases in impressionable company. There is evidence that teachers who favored some students over others harm students' efficacy, and over time, the influence of several 
unfair teachers can push students out of subjects that they might have previously wanted to pursue.

Policy that addresses educational inequalities around race and gender are still necessary to preserve the success we have achieved to make school more accessible and culturally responsive to social groups who have previously had poor, hostile experiences in school. However, we should continue to reflect on biases that are so ingrained in our culture that we fail to see where they still shape inequalities. Interventions should focus on addressing the gender bias that underlies so much of our expectations around students' performance and capabilities, especially because the persistence of educational inequalities indicates the need for continued efforts and intentional solutions. These changes may be as simple as disseminating information to professional development and planning efforts that already call for lessons and curriculum to address racial disparities. Adding interventions that urge educators to consider gender biases in their classrooms utilizes existing methods of making lessons accessible to different types of students. Small changes in the classroom can help in building students' confidence through lowrisk interactions and participation, which can compound over time to result in greater efficacy and an even more diverse body of future mathematicians. 


\section{Limitations}

With studies that utilize secondary data analysis, there is the possibility that an unintended sampling bias occurred during data collection that is beyond the control of this current study. It is also important to note that this dataset is meant to be representative of students who were in 9th grade in 2009, so there may be cohort effects that are unique to students in this population. If the findings in this study are due to a characteristic specific to this particular cohort, this means that they cannot be generalized to other grades or even to other high school students in other locations or time periods. Compared to older cohorts of students, the sample of high school students in this dataset could have less restrictive views about gender appropriate behaviors and industries. This more accepting mindset could be reflected in the findings from this study and how receptive students' attitudes about themselves and their academic potential in response to positive teacher interactions might not appear in samples of students from older generations who might more strictly adhere to cultural expectations around gender.

In creating my analytic sample, certain groups of students were excluded based on my selection criteria. Most of the characteristics between my analytic sample and the excluded cases were similar, though the students in the excluded cases were slightly more disadvantaged and had a slightly higher proportion of males. About $2 \%$ of students were not capable of completing the student questionnaire due to language barriers or severe disabilities in 2009, though the NCES retained these cases in the sample and sought out contextual data for these students. Though students who were deemed incapable of taking the survey were only a small portion of the total sample, it would be important in future 
research to adapt the survey for these students in this dataset or a smaller, separate dataset to understand how their experiences differ from a majority of high school students.

My exclusion criteria may have inadvertently failed to measure experiences of students who were comparatively unprepared in math or encountered unique academic challenges that is atypical of a US high school student. Students who come from households with a higher socioeconomic status tend to have more economic, social, and cultural capital from their parents or guardians to help them navigate school. This includes knowing when to reach out and get help from teachers or outside sources when necessary. Findings in this study, then, may be capturing perceptions of students who are more optimistic toward their capabilities and pathways in math, as the level of preparedness that a student has when they start a new math course can influence their classroom experience. A well-prepared student would likely encounter a greater frequency of positive interactions and emotional experiences than a student who was illprepared and required remedial work.

Regarding the males excluded from the sample based on my selection criteria, this could include students who were not enrolled in a math class or skipped questions that asked about perceptions of their math teacher for a variety of reasons. It is possible that boys were more frequently deemed incapable of taking the survey by the NCES, were selected and dropped out before the survey was administered, or were prepared for a level of math not offered to $9^{\text {th }}$ grade students. These are largely cases of academic outliers that would not be the experience of a typical high school student in the US and are not captured in the results of this study. Because these cases are so marginalized and a small 
proportion of the larger sample, their inclusion to my analytic sample might not affect my findings greatly and might better be captured in a smaller dataset or research design that allows for deeper data collection rather than the breadth of information enabled by nationally representative surveys.

Finally, the measures of students' math efficacy are taken from the fall of $9^{\text {th }}$ grade and the spring of $11^{\text {th }}$ grade, which means that students potentially had as many as three different math teachers in the time period between surveys. Thus, the relationship between students' experiences in 9th grade and their attitude in 11th grade may be underestimated since there is no way to account for the influence of the math teacher in between the two measures of math efficacy. A measure of students' math efficacy immediately after the completion of $9^{\text {th }}$ grade might find an even stronger relationship between their perceptions of their math teacher. Moving forward, it is important for studies that aim to understand teacher influences to capture information at crucial points in time, such as before students are introduced to more adults and faculty who may further shape their attitudes.

Despite these limitations, the longitudinal nature of this measure lends a strong causal argument to this study as opposed to a cross-sectional study that would not be able to make a clear causal relationship between students' math efficacy and perceptions of their math teacher's fairness. With this, results in this study can conclude that a student's math efficacy is affected by perceptions of math teachers with whom they have interacted. These findings only look at the effects of a single teacher but become more powerful when considering the context and structure of high school. Students typically 
interact with more than one teacher and more than one class in any given day at this level of education, which could potentially have an additive effect on their efficacy. Raising awareness of the small effect that teachers can have on students' efficacy can compound with multiple teachers working together to cultivate a learning environment that truly promotes the idea that students' potential is not restricted by their gender, race, or any other salient identity that previously imposed limits on students.

The strength of this study is not just in the causal argument enabled by the longitudinal research design, but also the random sample of a nationally representative population. Focusing on obtaining a sample that is representative of the larger population of US high school students makes these findings the meaningful for more people. A great majority of US high school students can benefit from the results in this study in that the findings can be used to influence policies and address concerns that affect the most students. 


\section{Conclusion}

This study finds that girls' efficacy in math benefits from constructive learning experiences in high school, even over the course of a little over a year. This also highlights the importance of positive interventions for girls in math from trusted sources on attitudes about their academic capabilities. These attitudes often play a pivotal role in decisions around high school courses and college programs that perpetuate gendered educational and occupational inequalities. It is vital that sources work together, such as field experts and students themselves, to confront the ideas behind negative stereotypes. Together, they can more accurately inform students' expectations about their true potential as academics and eventual members in the workforce to allow students' interests and choices, instead of conforming to societal expectations, to reflect their true passions. 


\section{References}

Alcock, Lara, Nina Attridge, Steven Kenny, and Matthew Inglis. 2014. "Achievement and Behaviour in Undergraduate Mathematics: Personality is a Better Predictor than Gender." Research in Mathematics Education 16(1):1-17.

Appleton, James J., Sandra L. Christenson, and Michael J. Furlong. 2008. "Student Engagement with School: Critical Concept and Methodological Issues of the Construct." Psychology in Schools 45(5):369-386.

Bagès, Céline and Delphine Martinot. 2011. "What is the Best Model For Girls and Boys Faced With a Standardized Mathematics Evaluation Situation: A Hardworking Role Model or a Gifted Role Model?" The British Journal of Social Psychology 50(3):536-543.

Barile, John P., Dana K. Donohue, Elizabeth R. Anthony, Andrew M. Baker, Scott R. Weaver, and Christopher C. Henrich. 2012. "Teacher-Student Relationship Climate and School Outcomes: Implications for Educational Policy Initiatives." Journal of Youth and Adolescence 41(3):256-67.

Beede, David, Tiffany Julian, and David Langdon. 2011. "Women in STEM : A Gender Gap to Innovation." US Department of Commerce, Economics and Statistics Administration. ESA \#04-11. Washington D.C. Economics and Statistics Administration.

Beilock, Sian L., Elizabeth A. Gunderson, Gerardo Ramirez, and Susan C. Levine. 2010. "Female Teachers' Math Anxiety Affects Girls' Math Achievement." PNAS 107(5):1860-1863.

Boaler, Jo and Tesha Sengupta-Irving. 2016. "The Many Colors of Algebra: The Impact of Equity Focused Teaching Upon Student Learning and Engagement." Journal of Mathematical Behavior 41(1):179-190.

Buchmann, Claudia, Thomas A. DiPrete, and Anne McDaniel. 2008. "Gender Inequalities in Education." Annual Review of Sociology 34(1):319-337.

Carrell, Scott E., Marianne E. Page, and James E. West. 2010. "Sex and Science: How Professor Gender Perpetuates the Gender Gap." The Quarterly Journal of Economics 125(3):1101-1144.

Cech, Erin, Brian Rubineau, Susan Silbey, and Caroll Seron. 2011. "Professional Role Confidence and Gendered Persistence in Engineering." American Sociological Review 76(5):641-666.

Chafetz, Janet S. 1997. "Feminist Theory and Sociology: Underutilized Contributions for Mainstream Theory." Annual Review of Sociology 23(1):97-120.

Cho, Insook. 2012. "The Effect of Teacher-Student Gender Matching: Evidence From OECD Countries.” Economics of Education Review 31(1):54-67.

Cordero, Elizabeth D., Sarah H. Porter, Tania Israel, and Michael T. Brown. 2010. "Math and Science Pursuits: A Self-Efficacy Intervention Comparison Study." Journal of Career Assessment 18(4):362-75.

Cornelius-White, Jeffrey. 2007. "Learner-Centered Teacher-Student Relationships Are Effective: A Meta-Analysis.” Review of Educational Research 77(1):113-143. 
Correll, Shelley J. 2001. "Gender and the Career Choice Process: The Role of Biased Self-Assessments.” American Journal of Sociology 106(6):1691-1730.

Cover, Ben, John I. Jones, and Audrey Watson. 2011. "Science, Technology, Engineering, and Mathematics (STEM) Occupations: A Visual Essay." Monthly Labor Review 6(1):3-15.

Dee, Thomas S. 2005. “A Teacher Like Me: Does Race, Ethnicity, or Gender Matter?" American Economic Review 95(2):158-165.

Dee, Thomas S. 2006. "The Why Chromosome: How a Teacher's Gender Affects Boys and Girls." Education Next 6(4):68-75.

Dee, Thomas S. 2007. "Teachers and the Gender Gaps in Student Achievement." The Journal of Human Resources 42(3):528-554.

Dubetz, Terry and Jo Ann Wilson. 2013. "Girls in Engineering, Mathematics, and Science, GEMS: A Science Outreach Program for Middle-School Female Students.” Journal of STEM Education 14(3):41-47.

Duncan-Andrade, Jeff. 2007. "Gangstas, Wankstas, and Ridas: Defining, Developing, and Supporting Effective Teachers in Urban Schools." International Journal of Qualitative Studies in Education 20(6):617-638.

Emamjomeh, Seyedeh Mahtab, and Masoud Bahrami. 2015. "Effect of a SupportiveEducation Program in the Math Class for Stress, Anxiety, and Depression in Female Students in the Third Level of Junior High School: An Action Research." Journal of Education and Health Promotion 4(1):10-16.

Falco, Lia D., Jessica J. Summers, and Sheri Bauman. 2010. "Encouraging Mathematics Participation Through Improved Self-Efficacy: A School Counseling Outcomes Study." Journal of Education Research and Evaluation 16(6):529-549.

Griffith, Amanda L. 2010. "Persistence of Women and Minorities in STEM Field Majors: Is It the School That Matters?" Economics of Education Review 29(1):911-922.

Gunderson, Elizabeth At., Gerardo Ramirez, Susan C. Levine, and Sian L. Beilock. 2012. "The Role of Parents and Teachers in the Development of Gender-Related Math Attitudes." Sex Roles 66(1):153-166.

Gundy, Karen Van, Beth A. Morton, Hope Q. Liu, and Jennifer Kline. 2006. "Effects of Web-Based Instruction on Math Anxiety, the Sense of Mastery, and Global SelfEsteem: A Quasi-Experimental Study of Undergraduate Statistics Students." Teaching Sociology 34(4):370:388.

Harris, Douglas N. and Tim R. Sass. 2011. "Teacher Training, Teacher Quality, and Student Achievement.” Journal of Public Economics 95(1):798-812.

Henry, Gary T., Kelly M. Purtell, Kevin C. Bastian, C. Kevin Fortner, Charles L. Thompson, Shanyce L. Campbell, and Kristina M. Patterson. 2014. "The Effects of Teacher Entry Portals on Student Achievement." Journal of Teacher Education 65(1):7-23.

Herbert, Jennifer and Deborah Stipek. 2005. "The Emergence of Gender Differences in Children's Perceptions of Their Academic Performance." Applied Developmental Psychology 26(1):276-295.

Holmes, Stephanie, Adrienne Redmond, Julie Thomas, and Karen High. 2012. "Girls Helping Girls: Assessing the Influence of College Student Mentors in an Afterschool 
Engineering Program." Mentoring \& Tutoring: Partnership in Learning 20(1):137150.

Howard, Nicol R. 2015. "The Influences of Mathematics Self-Efficacy, Identity, Interest, and Parental Involvement on STEM Achievement in Algebra for Female High School Students." PhD dissertation, College of Educational Studies, Chapman University.

Huguet, Pascal and Isabelle Régner. 2007. "Stereotype Threat Among Schoolgirls in Quasi-Ordinary Classroom Circumstances.” Journal of Educational Psychology 99(3):545-560.

Johnson, Heather J., Lucy Barnard-Brak, Terrill F. Saxon, and Megan K. Johnson. 2012. "An Experimental Study of the Effects of Stereotype Threat and Stereotype Lift on Men and Women's Performance in Mathematics." The Journal of Experimental Education 80(2):137-149.

Kamas, Linda and Anne Preston. 2012. “The Importance of Being Confident: Gender, Career Choice, and Willingness to Compete." Journal of Economic Behavior \& Organization 83(1):82-97.

Kelly, Sean and Yuan Zhang. 2016. "Teacher Support and Engagement in Math and Science: Evidence from the High School Longitudinal Study." The High School Journal 99(2):141-165.

Korur, Fikret and Ali Eryilmaz. 2012. "Teachers' and Students' Perceptions of Effective Physics Teacher Characteristics." Eurasian Journal of Education Research 46(1):101-20.

Landivar, Liana Christin. 2013. "Disparities in STEM Employment by Sex, Race, and Hispanic Origin." American Community Survey Reports, ACS-24, US Census Bureau, Washington DC.

Legewie, Joscha and Thomas A. DiPrete. 2012. "High School Environments, STEM Orientations, and the Gender Gap in Science and Engineering Degrees." $\mathrm{PhD}$ dissertation, Department of Sociology, Columbia University.

Lent, Robert W., Hung-Bin Sheu, Daniel Singley, Janet A. Schmidt, Linda C. Schmidt, and Clay S. Gloster. 2008. "Longitudinal Relations of Self-Efficacy to Outcome Expectations, Interests, and Major Choice Goals in Engineering Students." Journal of Vocational Behavior 73(1): 328-335.

Louis, Rachel A., and Jean M. Mistele. 2011. "The Differences in Scores and SelfEfficacy by Student Gender in Mathematics and Science." International Journal of Science and Mathematics Education 10(1):1163-1190.

Maloney, Erin A., Marjorie W. Schaeffer, and Sian L. Beilock. 2013. "Mathematics Anxiety and Stereotype Threat: Shared Mechanisms, Negative Consequences, and Promising Interventions." Research in Mathematics Education 15(2):115-128.

Marchand, Gwen C., and Antonio P. Gutierrez. 2017. "Processes Involving Perceived Instructional Support, Task Value, and Engagement in Graduate Education." The Journal of Experimental Education 85(1):87-106.

Muller, Patricia A., Frances K. Stage, and Jillian Kinzie. 2011. "Science Achievement Growth Trajectories: Understanding Factors Related to Gender and Racial-Ethnic Differences in Precollege Science Achievement." American Educational Research Journal 38(4):981-1012. 
Nguyen, Hannah-Hanh D., and Ann Marie Ryan. 2008. "Does Stereotype Threat Affect Test Performance of Minorities and Women? A Meta-Analysis of Experimental Evidence." Journal of Applied Psychology 93(6):1314-1334.

Nosek, Brian A., Mahzarain R. Banaji, and Anthony G. Greenwald. 2002. "Math = Male, $\mathrm{Me}=$ Female, Therefore Math $\neq$ Me." Journal of Personality and Social Psychology 83(1): 44-59.

Nosek, Brian A., Frederick L. Smyth, N. Sriram, Nicole M. Lidner, Thierry Devos, Alfonso Ayala, Yoav Bar-Anan, Robin Bergh, Huajian Cal, Karen Gonsalkorale, Selin Kesebir, Normert Maliszewski, Félix Neto, Eero Olli, Jaihyun Park, Konrad Schnabel, Kimihiro Shiomura, Bodhan Tudor Tulbure, Reinout W. Weirs, Mónika Somogyi, Nazar Akrami, Bo Ekehammar, Michelangelo Vianello, Mahzarin R. Banaji, and Anthony G. Greenwald. PNAS 106(26):10593-10597.

Patrick, Helen, Allison M. Ryan, and Avi Kaplan. 2007. “Early Adolescents' Perceptions of the Classroom Social Environment, Motivational Beliefs, and Engagement." Journal of Educational Psychology 99(1):83-98.

Peterson, E. R., C. Rubie-Davies, D. Osborne, and C. Sibley. 2016. “Teachers' Explicit Expectations and Implicit Prejudiced Attitudes to Educational Achievement: Relations with Student Achievement and the Ethnic Achievement Gap." Learning and Instruction 42(1):123-140.

Price, Joshua. 2010. "The Effect of Instructor Race and Gender on Student Persistence in STEM Fields." Economics of Education Review 29(1):901-910.

Riegle-Crumb, Catherine and Melissa Humphries. 2012. "Exploring Bias in Math Teachers' Perceptions of Students' Ability by Gender and Race/Ethnicity." Gender \& Society 26(2):290-322.

Riegle-Crumb, Catherine, Barbara King, Eric Grodsky, and Chandra Muller. 2012. "The More Things Change: the More They Stay the Same? Prior Achievement Fails to Explain Gender Inequality in Entry Into STEM College Majors Over Time." American Educational Research Journal 49(6):1048-1073.

Robinson-Cimpian, Joseph P., Sarah Theule Lubienski, Colleen M. Ganley, and Yasemin Copur-Gencturk. 2014. “Teachers' Perceptions of Students' Mathematics Proficiency May Exacerbate Early Gender Gaps in Achievement." Developmental Psychology 50(4):1262-1281.

Roorda, Deborah. L., Helma M. Y. Koomen, Jantine. L. Spilt, and Frans. J. Oort. 2011. "The Influence of Affective Teacher-Student Relationships on Students' School Engagement and Achievement: A Meta-Analytic Approach." Review of Educational Research 81(4):493-529.

Salter, Daniel W., and Anita Persaud. 2003. "Women's Views of the Factors That Encourage and Discourage Classroom Participation." Journal of College Student Development 44(6):831-844.

Shapiro, Jenessa R. and Amy M. Williams. 2012. "The Role of Stereotype Threat in Undermining Girls' and Women's Performance and Interest in STEM Fields." Sex Roles 66(1):175-183. 
Spencer, Steven J., Claude M. Steele, and Diane M. Quinn. 1999. "Stereotype Threat and Women's Math Performance." Journal of Experimental Social Psychology 35(1):428.

Tyler-Wood, Tandra, Amber Ellison, Okyoung Lim, and Sita Periathiruvadi. 2012.

"Bringing Up Girls in Science (BUGS): The Effectiveness of an Afterschool Environmental Science Program for Increasing Female Students' Interest in Science Careers". Journal of Science Education \& Technology 21(1):46-55.

Upadyaya, Katja and Jacquelynne Eccles. 2015. 'Do Teachers' Perceptions of Children's Math and Reading Related Ability and Effort Predict Children's Self-Concept of Ability in Math and Reading?" International Journal of Experimental Educational Psychology 35(1):110-127.

Wenglinsky, Harold. 2002. "How Schools Matter: The Link Between Teacher Classroom Practices and Student Academic Performance." Education Policy Analysis Archives 10(12):1-30.

Winters, Marcus A., Robert C. Haight, Thomas T. Swain, and Katarzyna A. Pickering. 2013. "The Effect of Same-Gender Teacher Assignment on Student Achievement in the Elementary and Secondary Grades: Evidence From Panel Data." Economics of Education Review 34(1):69-75. 


\section{Appendix}

\begin{tabular}{|c|c|c|}
\hline & Selected & Excluded \\
\hline \multirow[t]{2}{*}{ Student perception of math teacher fairness in 2009} & 3.15 & 3.09 \\
\hline & $(0.56)$ & $(0.55)$ \\
\hline \multirow[t]{2}{*}{ Student math efficacy in 2009} & 0.01 & 0.01 \\
\hline & $(0.93)$ & $(0.88)$ \\
\hline \multirow[t]{2}{*}{ Student pride in school } & 3.14 & 3.09 \\
\hline & $(0.74)$ & $(0.78)$ \\
\hline \multirow[t]{2}{*}{ Student math achievement } & 39.89 & 33.79 \\
\hline & $(11.80)$ & $(11.92)$ \\
\hline Student intention to pursue bachelor's degree & 0.51 & 0.43 \\
\hline Female math teacher & 0.71 & 0.71 \\
\hline \multicolumn{3}{|l|}{ Math course } \\
\hline Lower than algebra 1 & 0.09 & 0.16 \\
\hline Algebra 1 & 0.61 & 0.59 \\
\hline Geometry & 0.21 & 0.14 \\
\hline Higher than geometry & 0.09 & 0.11 \\
\hline \multicolumn{3}{|l|}{ Student race } \\
\hline White & 0.52 & 0.41 \\
\hline Black & 0.13 & 0.24 \\
\hline Hispanic & 0.22 & 0.25 \\
\hline Asian & 0.03 & 0.04 \\
\hline Other & 0.09 & 0.06 \\
\hline \multirow[t]{2}{*}{ Household income } & 3.66 & 2.96 \\
\hline & $(2.65)$ & $(2.39)$ \\
\hline \multicolumn{3}{|l|}{ Mother's educational attainment } \\
\hline No mother & 0.05 & 0.04 \\
\hline Less than high school & 0.07 & 0.10 \\
\hline High school/GED & 0.56 & 0.68 \\
\hline Some college & 0.11 & 0.07 \\
\hline Bachelor's degree & 0.14 & 0.10 \\
\hline More than a bachelor's degree & 0.06 & 0.02 \\
\hline \multicolumn{3}{|l|}{ Father's educational attainment } \\
\hline No father & 0.18 & 0.16 \\
\hline Less than high school & 0.06 & 0.10 \\
\hline High school/GED & 0.52 & 0.62 \\
\hline
\end{tabular}


Some college

Bachelor's degree

More than a bachelor's degree

Mother's occupation

No mother

Mother not in STEM

Mother in STEM

Father's occupation

No father

Father not in STEM

Father in STEM

School locale

City

Suburb

Town

Rural

School region

Northeast

South

Midwest

West

$\begin{array}{ll}0.07 & 0.02 \\ 0.11 & 0.06 \\ 0.07 & 0.04\end{array}$

$\begin{array}{ll}0.08 & 0.08\end{array}$

$0.87 \quad 0.83$

$0.05 \quad 0.09$

$0.18 \quad 0.18$

$\begin{array}{ll}0.74 & 0.77\end{array}$

$0.08 \quad 0.05$

$\begin{array}{ll}0.32 & 0.42\end{array}$

$0.33 \quad 0.36$

$0.12 \quad 0.08$

$0.23 \quad 0.15$

$\begin{array}{ll}0.17 & 0.23\end{array}$

$0.38 \quad 0.40$

$0.22 \quad 0.22$

$0.23 \quad 0.15$

$\mathrm{n}=20,078 \quad \mathrm{n}=3,425$

Note: Values in parentheses are standard deviations. All variables are from 2009 unless otherwise specified. Science, technology, engineering, and mathematics is abbreviated to "STEM". General educational development degree is abbreviated to "GED". 
Table 2: Descriptive statistics of gender-separated models

Student perception of math teacher fairness in 2009

\begin{tabular}{cc} 
Female & Male \\
\hline 3.19 & 3.17 \\
$(0.52)$ & $(0.53)$ \\
-0.01 & 0.14 \\
$(0.89)$ & $(0.87)$
\end{tabular}

Student pride in school

3.19

3.17

(0.69)

$(0.71)$

Student math achievement

40.87

40.98

(10.96)

(11.58)

Student intention to pursue bachelor's degree

63.0

56.6

Female math teacher

0.71

0.71

Math course

Lower than algebra 1

0.08

0.07

Algebra 1

0.44

0.44

Geometry

0.21

0.19

Higher than geometry

0.10

0.10

Student race

White

0.57

0.57

Black

0.10

0.10

Hispanic

0.16

0.15

Asian

0.08

0.08

Other

0.09

0.09

Household income

4.01

4.01

(2.85)

(2.90)

Mother's educational attainment

No mother

0.05

0.05

Less than high school

0.05

0.05

High school/GED

0.53

0.54

Some college

0.11

0.11

Bachelor's degree

0.17

0.17

More than a bachelor's degree

0.09

0.08

Father's educational attainment

No father

0.17

0.15

Less than high school

0.05

0.05

High school/GED

0.49

0.51

Some college

0.07

0.07

Bachelor's degree

0.13

0.13

More than a bachelor's degree

0.10 
Mother's occupation

No mother

$\begin{array}{ll}0.08 & 0.08\end{array}$

Mother not in STEM

$0.82 \quad 0.82$

Mother in STEM

0.11

0.11

Father's occupation

No father

0.17

0.16

Father not in STEM

0.73

0.74

Father in STEM

0.10

0.10

School locale

City

$\begin{array}{ll}0.29 & 0.28\end{array}$

Suburb

0.36

0.36

Town

0.12

0.12

Rural

0.24

0.24

School region

Northeast

0.16

0.15

South

0.26

0.27

Midwest

0.40

0.42

West

0.17

0.16

$\mathrm{n}=9,987$

$\mathrm{n}=10,091$

Note: Values in parentheses are standard deviations. All variables are from 2009 unless otherwise specified. Science, technology, engineering, and mathematics is abbreviated to "STEM". General educational development degree is abbreviated to "GED". 
Table 3: Linear regression models predicting female students' math efficacy in 2012

Student perception of math
teacher fairness

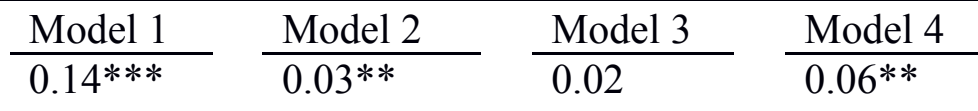
teacher fairness

Student math efficacy

$\begin{array}{lll}(0.01) & (0.01) & (0.02) \\ 0.24 * * * & 0.21^{* * *} & 0.21^{* * *} \\ (0.01) & (0.01) & (0.01) \\ & 0.03^{* *} & 0.03^{* *} \\ & (0.01) & (0.01) \\ & 0.01 * * * & 0.01 * * * \\ & (0.00) & (0.00) \\ & 0.02 & 0.02\end{array}$

bachelor's degree

$\begin{array}{ll}(0.01) & (0.01) \\ 0.00 & 0.16^{*} \\ (0.02) & (0.09)\end{array}$

Math course

Less than algebra 1

$\begin{array}{ll}0.02 & 0.02 \\ (0.03) & (0.03)\end{array}$

Algebra 1 (ref)

Geometry

$-$

0.01

0.01

$(0.02)$

Higher than geometry

0.02

0.02

(0.02)

$(0.02)$

Student perception of math $-0.05^{*}$

teacher fairness $\mathrm{x}$ Female math teacher

$\begin{array}{lll}\text { Student race } & & \\ \text { White (ref) } & - & - \\ \text { Black } & 0.17^{* * *} & 0.17^{* * *} \\ & (0.02) & (0.02) \\ \text { Hispanic } & 0.08^{* * *} & 0.08^{* * *} \\ & (0.02) & (0.02) \\ \text { Asian } & 0.10^{* * *} & 0.10^{* * *} \\ & (0.03) & (0.03) \\ \text { Other } & 0.05^{*} & 0.05^{*} \\ & (0.02) & (0.02)\end{array}$

Mother's educational attainment 


\begin{tabular}{|c|c|c|}
\hline No mother & $\begin{array}{l}0.07 \\
(0.05)\end{array}$ & $\begin{array}{l}0.07 \\
(0.05)\end{array}$ \\
\hline Less than high school & $\begin{array}{l}0.00 \\
(0.03)\end{array}$ & $\begin{array}{l}0.00 \\
(0.03)\end{array}$ \\
\hline High school/GED (ref) & - & - \\
\hline Some college & $\begin{array}{l}0.01 \\
(0.02)\end{array}$ & $\begin{array}{l}0.01 \\
(0.02)\end{array}$ \\
\hline Bachelor's degree & $\begin{array}{l}0.01 \\
(0.02)\end{array}$ & $\begin{array}{l}0.01 \\
(0.02)\end{array}$ \\
\hline $\begin{array}{l}\text { More than a bachelor's } \\
\text { degree }\end{array}$ & $\begin{array}{l}-0.04 \\
(0.03)\end{array}$ & $\begin{array}{l}-0.04 \\
(0.03)\end{array}$ \\
\hline \multicolumn{3}{|l|}{$\begin{array}{l}\text { Father's educational } \\
\text { attainment }\end{array}$} \\
\hline No father & $\begin{array}{l}-0.01 \\
(0.08)\end{array}$ & $\begin{array}{l}-0.11 \\
(0.08)\end{array}$ \\
\hline Less than high school & $\begin{array}{l}0.06+ \\
(0.03)\end{array}$ & $\begin{array}{l}0.06+ \\
(0.03)\end{array}$ \\
\hline High school/GED (ref) & - & - \\
\hline Some college & $\begin{array}{l}-0.01 \\
(0.03)\end{array}$ & $\begin{array}{l}-0.02 \\
(0.03)\end{array}$ \\
\hline Bachelor's degree & $\begin{array}{l}0.03 \\
(0.03)\end{array}$ & $\begin{array}{l}0.03 \\
(0.03)\end{array}$ \\
\hline $\begin{array}{l}\text { More than a bachelor's } \\
\text { degree }\end{array}$ & $\begin{array}{l}0.02 \\
(0.03)\end{array}$ & $\begin{array}{l}0.02 \\
(0.03)\end{array}$ \\
\hline Household income & $\begin{array}{l}0.00 \\
(0.00)\end{array}$ & $\begin{array}{l}0.00 \\
(0.00)\end{array}$ \\
\hline $\begin{array}{l}\text { Mother's occupation - } \\
\text { STEM }\end{array}$ & $(0.02)$ & $(0.02)$ \\
\hline No mother & $\begin{array}{l}-0.08+ \\
(0.04)\end{array}$ & $\begin{array}{l}-0.07+ \\
(0.04)\end{array}$ \\
\hline Mother not in STEM (ref) & - & - \\
\hline Mother in STEM & $\begin{array}{l}0.00 \\
(0.02)\end{array}$ & $\begin{array}{l}0.00 \\
(0.02)\end{array}$ \\
\hline \multicolumn{3}{|l|}{ Father's occupation - STEM } \\
\hline No father & $\begin{array}{l}0.12 \\
(0.08)\end{array}$ & $\begin{array}{l}0.12 \\
(0.08)\end{array}$ \\
\hline Father not in STEM (ref) & - & - \\
\hline Father in STEM & 0.01 & 0.01 \\
\hline
\end{tabular}


School locale

City

$0.03+\quad 0.03+$

Suburb (ref)

(0.02)

Town

$-0.03$

$-0.03$

$(0.02)$

Rural

0.01

0.01

(0.02)

School region

Northeast

$-0.01$

$-0.01$

$(0.02)$

South

$-0.03+$

Midwest (ref)

(0.02)

West

Constant

$2.24 * * *$

$-$

$-0.10^{* * *}$

$-0.10 * * *$

R-squared

0.01

$2.59^{* * *}$

$2.15^{* * *}$

$2.03 * * *$

Note: 9,987 female students were used in these analyses. Values in parentheses are standard deviations. All variables are from 2009 unless otherwise specified. Science, technology, engineering, and mathematics is abbreviated to "STEM". General educational development degree is abbreviated to "GED".

$\mathrm{p}+<0.10, \mathrm{p}^{*}<0.05, \mathrm{p}^{* *}<0.01, \mathrm{p}^{* * *}<0.001$. 


\begin{tabular}{|c|c|c|c|c|}
\hline \multirow{3}{*}{$\begin{array}{l}\text { Student perception of } \\
\text { math teacher fairness }\end{array}$} & Model 1 & Model 2 & Model 3 & Model 4 \\
\hline & $0.15^{* * *}$ & $0.03 * *$ & 0.00 & -0.02 \\
\hline & $(0.01)$ & $(0.01)$ & $(0.01)$ & $(0.02)$ \\
\hline \multirow[t]{2}{*}{ Student math efficacy } & & $0.27 * * *$ & $0.21 * * *$ & $0.21 * * *$ \\
\hline & & $(0.01)$ & $(0.01)$ & $(0.01)$ \\
\hline \multirow[t]{2}{*}{ Student pride in school } & & & $0.05 * * *$ & $0.05 * * *$ \\
\hline & & & $(0.01)$ & $(0.01)$ \\
\hline \multirow{2}{*}{$\begin{array}{l}\text { Student math } \\
\text { achievement }\end{array}$} & & & $0.01 * * *$ & $0.01 * * *$ \\
\hline & & & $(0.00)$ & $(0.00)$ \\
\hline \multirow{2}{*}{$\begin{array}{l}\text { Student intention to } \\
\text { pursue bachelor's degree }\end{array}$} & & & $0.04 * *$ & $0.04 * *$ \\
\hline & & & $(0.01)$ & $(0.01)$ \\
\hline \multirow[t]{2}{*}{ Female math teacher } & & & 0.01 & -0.11 \\
\hline & & & $(0.01)$ & $(0.09)$ \\
\hline \multicolumn{5}{|l|}{ Math course } \\
\hline \multirow[t]{2}{*}{ Less than algebra 1} & & & -0.01 & -0.01 \\
\hline & & & $(0.03)$ & $(0.03)$ \\
\hline Algebra 1 (ref) & & & - & - \\
\hline \multirow[t]{2}{*}{ Geometry } & & & 0.06 & $0.06 * *$ \\
\hline & & & $(0.02)$ & $(0.02)$ \\
\hline \multirow[t]{2}{*}{ Higher than geometry } & & & 0.03 & 0.03 \\
\hline & & & $(0.02)$ & $(0.02)$ \\
\hline \multirow{3}{*}{$\begin{array}{l}\text { Student perception of } \\
\text { math teacher fairness } \mathrm{x} \\
\text { Female math teacher }\end{array}$} & & & & 0.04 \\
\hline & & & & \\
\hline & & & & $(0.02)$ \\
\hline \multicolumn{5}{|l|}{ Student race } \\
\hline White (ref) & & & - & - \\
\hline \multirow[t]{2}{*}{ Black } & & & $0.14^{* * *}$ & $0.14 * * *$ \\
\hline & & & $(0.02)$ & $(0.02)$ \\
\hline \multirow[t]{2}{*}{ Hispanic } & & & $0.07 * * *$ & $0.07 * * *$ \\
\hline & & & $(0.02)$ & $(0.02)$ \\
\hline \multirow[t]{2}{*}{ Asian } & & & $0.05^{*}$ & $0.05^{*}$ \\
\hline & & & $(0.02)$ & $(0.02)$ \\
\hline \multirow[t]{2}{*}{ Other } & & & $0.04+$ & $0.05+$ \\
\hline & & & $(0.02)$ & $(0.02)$ \\
\hline Household income & & & 0.00 & 0.00 \\
\hline
\end{tabular}


Mother's educational

attainment

No mother

$-0.06$

$-0.07$

Less than high school

$(0.05)$

(0.05)

0.01

0.02

High school/GED (ref)

(0.03)

(0.03)

Some college

$-$

$-0.02$

$-0.02$

$(0.02)$

$(0.02)$

Bachelor's degree

$-0.01$

$-0.01$

More than a bachelor's

(0.02)

(0.02)

degree

0.04

0.04

Father's educational

attainment

No father

$$
0.00
$$

0.00

Less than high school

(0.08)

$-0.05+$

$-0.05+$

(0.03)

(0.03)

High school/GED (ref)

Some college

$$
-
$$

$-0.05+$

-

$(0.03)$

$-0.05$

Bachelor's degree

$-0.01$

$(0.03)$

(0.02)

$-0.01$

More than a bachelor's

degree

$-0.01$

(0.02)

(0.03)

$-0.01$

Mother's occupation -

STEM

No mother

0.05

(0.04)

0.05

Mother not in STEM

(ref)

Mother in STEM

0.03

0.03

(0.02)

(0.02)

Father's occupation -

STEM

No father

$-0.04$

$-0.04$

(0.07)

(0.07) 
Father not in STEM

(ref)

Father in STEM

$0.05+\quad 0.05+$

(0.02) (0.02)

School locale

City

$\begin{array}{ll}0.01 & 0.01 \\ (0.02) & (0.02) \\ - & - \\ -0.05^{*} & -0.05^{*} \\ (0.02) & (0.02) \\ -0.02 & -0.02 \\ (0.02) & (0.02)\end{array}$

School region

Northeast

$0.01 \quad 0.01$

South

$(0.02)$

$(0.02)$

South

0.02

0.02

Midwest (ref)

(0.02)

(0.02)

West

$-$

Constant

$2.39 * * *$

$-0.02$

$-$

R-squared

0.01

$2.71 * * *$

$2.17 * * *$

$-0.02$

Note: 10,091 male students were used in these analyses. Values in parentheses are standard deviations. All variables are from 2009 unless otherwise specified. Science, technology, engineering, and mathematics is abbreviated to "STEM". General educational development degree is abbreviated to "GED".

$\mathrm{p}^{+}<0.10, \mathrm{p}^{*}<0.05, \mathrm{p}^{* *}<0.01, \mathrm{p}^{* * *}<0.001$ 


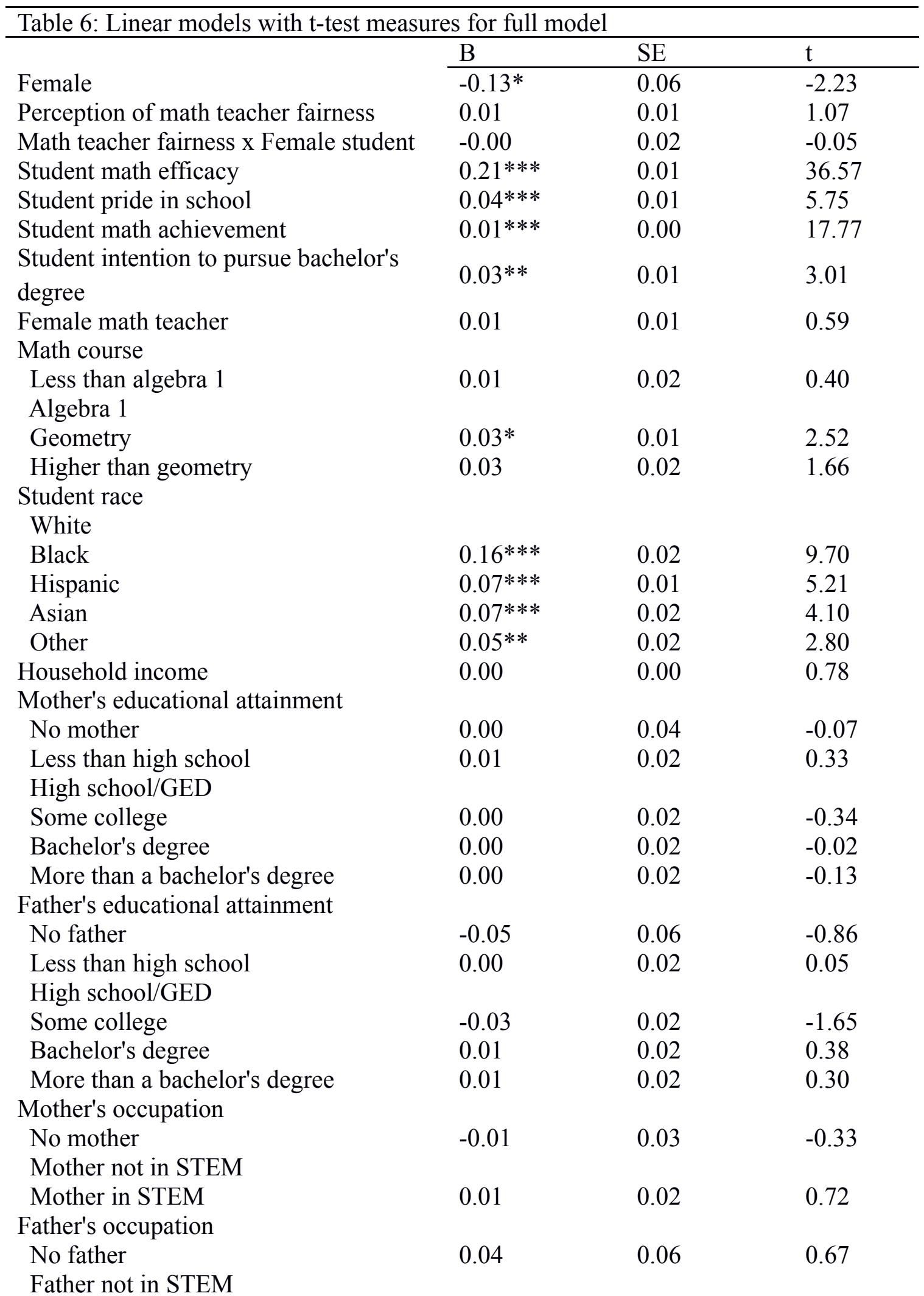


Father in STEM

$0.03 \quad 0.02$

1.53

School locale

City

0.02

0.01

1.60

Suburb

Town

$-0.04 *$

0.02

$-2.45$

Rural

$-0.01$

0.01

$-0.41$

School region

Northeast

South

0.00

0.01

0.32

Midwest

West

$-0.01$

0.01

$-0.58$

Constant

$-0.06 * * *$

0.01

$-4.10$

$2.21 * * *$

0.05

45.49

Note: Science, technology, engineering, and mathematics is abbreviated to "STEM". General educational development degree is abbreviated to "GED". $\mathrm{p}^{+}<0.10, \mathrm{p}^{*}<0.05, \mathrm{p}^{* *}<0.01, \mathrm{p}^{* * *}<0.001$. 
Figure 1: Female students' predicted mean values of math efficacy by math teacher gender

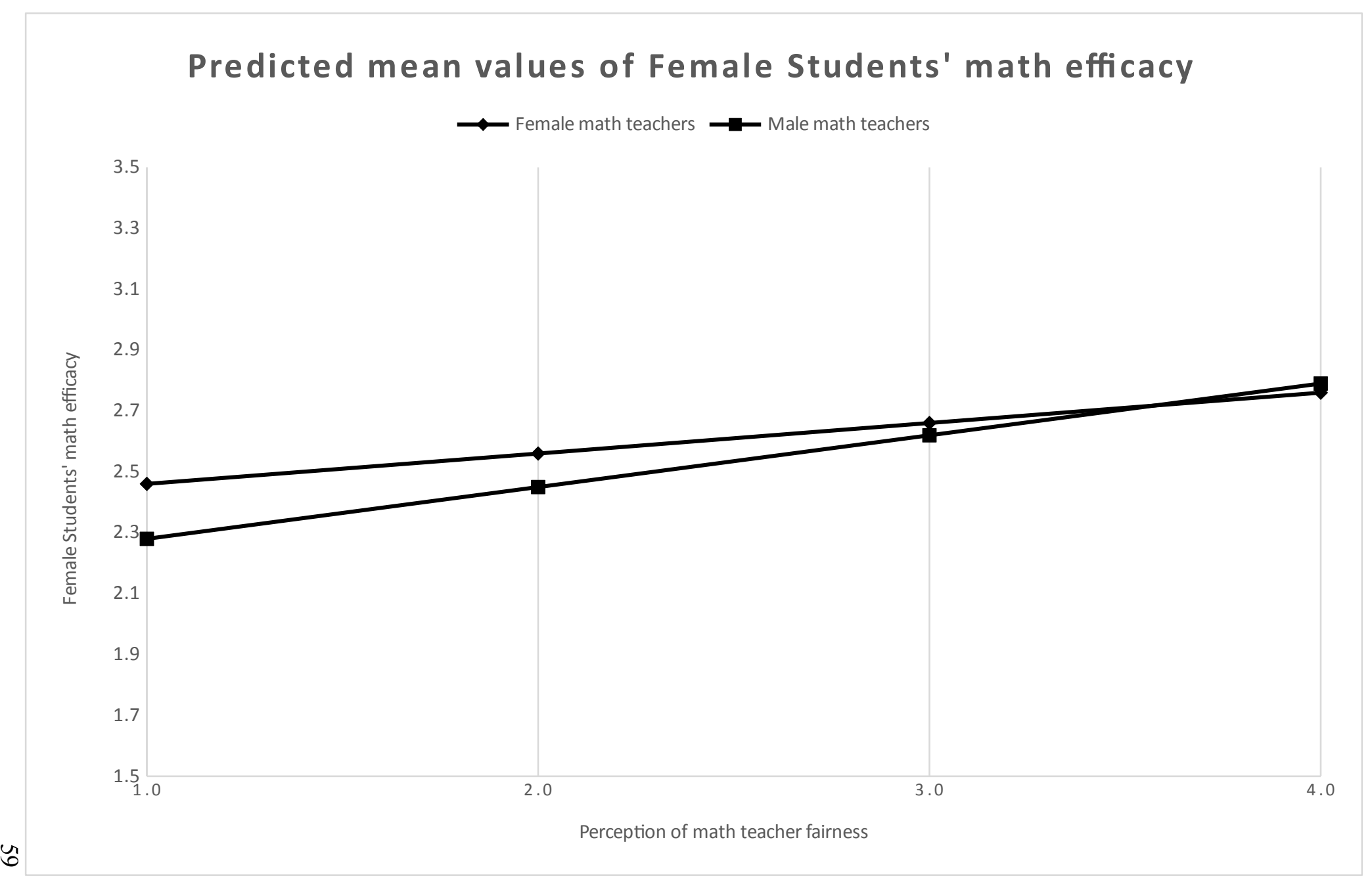

